\title{
Congenital megacalyces presenting as neonatal hydronephrosis
}

\author{
Woseneneh Bekele • Thomas R. Sanchez
}

Received: 4 February 2010 /Accepted: 23 February 2010/Published online: 7 May 2010

(C) The Author(s) 2010. This article is published with open access at Springerlink.com

An 8-year-old boy presented with a history of congenital hydronephrosis. The postnatal sonogram showed an enlarged right kidney with cortical thinning and markedly dilated calyces without associated pelviectasis (Fig. 1). Intravenous pyelogram confirmed the marked right calyceal dilatation. The pelvis and ureters were normal and there was no evidence of obstruction, with prompt and fairly symmetric opacification of the upper collecting systems (Fig. 2).

Congenital megacalyces is a rare cause of renal medullary dysplasia. The dilated calyces appear faceted and polygonal in contrast to the ballooned and spherical calyces of obstructive hydronephrosis. This condition is benign and nonprogressive, with near-normal renal function. The key to distinguishing this is that the pelvis and ureter appear normal without

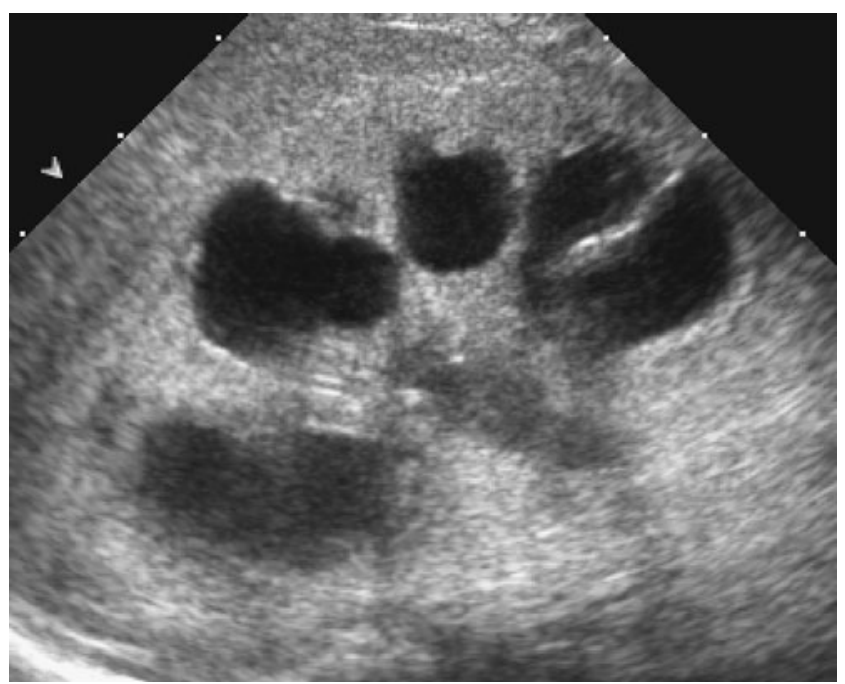

Fig. 1 US image of the right kidney

W. Bekele · T. R. Sanchez $(\bowtie)$

Department of Radiology, University of California-Davis,

4860 Y St., Suite 3100 ,

Sacramento, CA 95817, USA

e-mail: thomas.sanchez@ucdmc.ucdavis

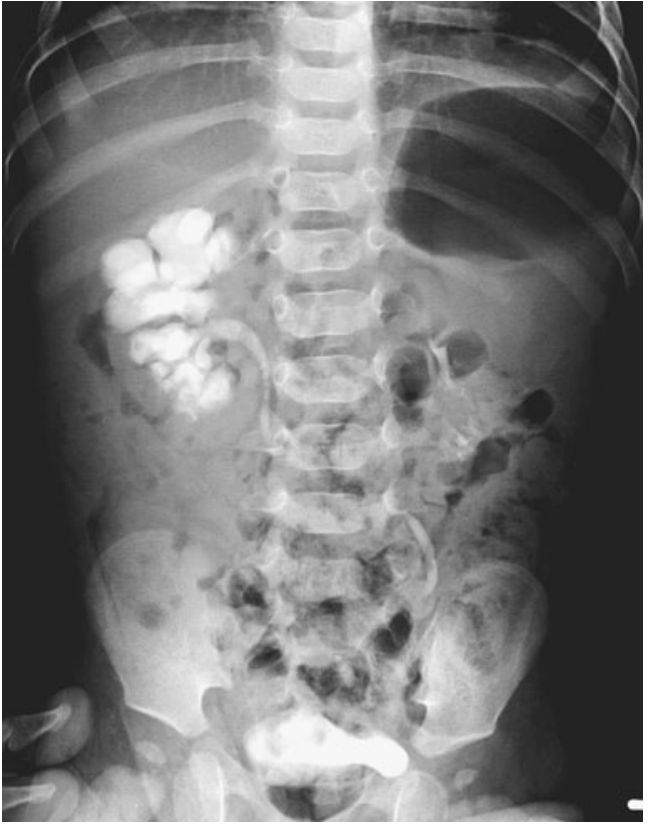

Fig. 2 Intravenous pyelogram

evidence of obstruction. It is important to differentiate this rare condition from the more common obstructive hydronephrosis to avoid unnecessary surgical intervention.

Open Access This article is distributed under the terms of the Creative Commons Attribution Noncommercial License which permits any noncommercial use, distribution, and reproduction in any medium, provided the original author(s) and source are credited.

\section{References}

1. Kozakewich HP, Lebowitz RL (1974) Congenital megacalyces. Pediatri Radiol 2:251-257

2. Pieretti-Vanmarcke R, Pieretti A, Pieretti RV (2009) Megacalycosis: a rare condition. Pediatr Nephrol 24:1077-1079 